\title{
Repensar les nostres arrels: la citricultura a Borriana
}

\author{
Pablo Urbaneja Bernat (paurbaneja@gmail.com) \\ Institut Valencià d'Investigacions Agràries \\ Universitat Jaume I
}

\section{Introducció}

Si Borriana ha estat un poble pròsper els darreres dos segles, li ho devem a la taronja. I és que aquest poble ha estat un dels majors exportadors de taronja del món. De fet, en la memòria collectiva borrianenca es recorda que cap l'any 1935, a París, Borriana era tan coneguda com València. Encara avui, és difícil de trobar algú que no en tinga cap parent o amic relacionat amb el cultiu o amb la comercialització d'aquest apreciat fruit de la família dels cítrics. Aquest capítol gira al voltant del que ha estat l'agricultura a Borriana durant els darrers dos segles i de quines són les possibilitats de futur.

\section{El passat de la taronja: evolució, origen i difusió}

A Borriana, l'agricultura actual és fruit d'una evolució duta a terme durant diverses etapes, en les quals es pot distingir entre productes de subsistència i productes comercials, que canvien segons les èpoques. La competència amb altres zones agrícoles i les demandes de mercat han originat canvis, als quals els llauradors locals sempre s'han intentat adaptar. Al segle XIX, el desenvolupament de les comunicacions i del comerç accelerà l'especialització i disminuïren els conreus de blat $i$ ordi. Lolivera, la morera i la vinya quedaren per al secà, i el cànem i la seda dominaren la primera meitat del segle XIx. Més endavant, aquests cultius donaren pas a la taronja, que finalment es va convertir en monocultiu (López, 1957). A partir d'aquest canvi progressiu, Borriana es va convertir en localitat capdavantera en la comercialització de la taronja, més que en el cultiu, el qual era compartit per altres pobles de la comarca.

És sabut que els cítrics són originaris del sud-est asiàtic i que els musulmans els introduïren per Andalusia, Múrcia i València (Roca, 1932), però sempre amb una única intenció ornamental, sense finalitat d'explotació agroalimentària (Font de Mora, 1971). És pels volts de 1780 quan aparegueren els primers tarongers a Borriana, plantats de manera aïllada com a complement de l'activitat agrícola principal. Probablement, les primeres plantacions regulars es feren a Vila-real a finals del segle XVIII, des d'on s'estengueren fins a Almassora i Borriana (Abad, 1984). Amb posterioritat, es formà un nucli citrícola a la Plana de Castelló, que amb l'altre nucli format a la Ribera Alta, van estendre el cultiu del taronger i la comercialització de la taronja per altres comarques i localitats arreu del País Valencià; una expansió ininterrompuda fins fa ben poc.

$\mathrm{Al}$ segle $\mathrm{xx}$, el taronger es consolida definitivament a la nostra terra, però a mitjan segle comencen a haver-hi dificultats en aquesta consolidació, sobretot pel que fa a la 
producció: l'atac de poll roig (Chrysomphalus dictyospermi, Hemiptera: Diaspididae) afectà greument tota la Plana (López, 1957). Superada aquesta dificultat, l'expansió del taronger a Borriana va continuar. Es dugueren a terme transformacions importants de marjals i de secans, de manera que quedaren preparats excel-lents terrenys regats per la séquia del Millars (Sarthou, 1989).

La primera guerra mundial (1914-1918) va dur una greu crisi al sector, fet que va frenar l'expansió del taronger. A aquests factors es van sumar l'encariment i l'escassesa d'adobs i d'insecticides, a més del baix preu pagat als llauradors per les collites. Arran d'açò, es van abandonar alguns horts i els llauradors van haver de demanar préstecs per a seguir mantenint la producció a la Plana (Abad, 1984). Però es va fer aleshores evident, per primera vegada, el perill provocat per la dependència del monocultiu de la taronja a Borriana, atès que quasi tots els sectors econòmics giraven al voltant d'aquest. Superada la guerra, es va tornar a produir un augment de les exportacions en el sector i, parallelament, es va incrementar la superfície conreada.

L'any 1936 tornaren les complicacions, ara per causa de la guerra civil, que va durar tres anys. Però després de la guerra no s'acabaren les dificultats. Les terres tornaren als propietaris, però la producció tarongera es va trobar amb carència d'adobs, problema que va tardar a solucionar-se. Quan els camps ja semblava que reviscolaven, va arribar la gelada de febrer de 1946. Aquesta gelada, que va afectar tota la Plana, va afectar greument el sudoest del terme de Borriana, fins al punt que es van haver d'arrancar molts tarongers gelats. La situació social i econòmica es tornà molt difícil en general, i més per a un municipi econòmicament basat en el monocultiu de la taronja durant els anys de postguerra o anys de la fam (Aparici, 1993).

A partir dels anys 60 s'inicia una transformació de la marjal que provoca l'abandonament definitiu del cultiu d'hortalisses per a plantar encara més tarongers. A començament dels anys 70 s'engega un dilatat procés de canvi de les varietats cultivades que condueix a l'augment del cultiu de les mandarines en detriment de les taronges.

És interessant d'observar el màrqueting sobre la taronja com a producte estrella que es duia a terme en els majors anys de puixança del negoci cítric a Borriana, sobretot en diverses etapes de la primera meitat del segle xx. Els distribuïdors de taronges i de mandarines d'aquesta època no es quedarien enrere si comparem les campanyes de promoció del seu producte, nacionals i a l'estranger, que duien a terme, en comparació amb el poc de màrqueting que, en general, té el producte estrella borrianenc. Sobta veure la riquesa artística, l'abundància i la diversitat de les etiquetes característiques de l'època $i$ fins i tot dels papers d'estrassa amb què s'embolica la taronja en alguns caixons. Borriana era aleshores capdavantera de l'exportació cítrica.

\section{El present de la taronja: actualitat citrícola}

\subsection{Importància econòmica}

Les espècies de cítrics d'interès comercial en el sector agroalimentari, que són les que han ocupat la marjal borrianenca de bell antuvi, pertanyen al gènere Citrus, etiqueta que inclou les espècies més importants des del punt de vista agronòmic, com ara el mandarí 
(Citrus reticulata) o el taronger (Citrus sinensis), entre d'altres. Els mandarins s'agrupen en tres grups: satsumes, híbrids i clementins; aquest últim és el de més importància econòmica a la Plana.

El sector agrari del País Valencià està molt especialitzat. De fet, és a terres valencianes on es realitza el $70 \%$ de la producció citrícola de tota la Península Ibèrica. A més, el País Valencià és també el major productor i exportador de mandarina i de taronja dolça d'Espanya (MAGRAMA, 2012). L'exportació de cítrics al País Valencià se centra a València, amb un 61\%; seguida de Castelló, amb el $31 \%$ de la producció, i d'Alacant, amb el 8\% (IVEX, 2013). Els productes cítrics valencians més exportats són, amb un 55\%, les mandarines, amb el $38 \%$ les taronges, amb el $6 \%$ les llimes i 1'1\% els pomelos. La superfície emprada per als cítrics, a la Plana, és de 40.182 hectàrees i la producció, per tipus, és de 512.676 tones de mandarines, 94.726 tones de taronger dolç, 304 tones de llimes i 30 tones de pomelos (IVEX, 2013).

La superfície total utilitzada per a l'agricultura a Borriana és de 4.668 hectàrees, de les quals el $84 \%$ es troba ocupat pels cítrics (3.900 hectàrees). La resta de terreny es troba ocupat primordialment per aigua en séquies i per basses de reg dels camps, per terrenys improductius com ara solars, per terrenys a mig urbanitzar, males herbes i canyars i, finalment, hortalisses, fruiters i altres cultius herbacis que poden trobar-se en horts d'oci o familiars. A més, el $90 \%$ de la superfície local total de les explotacions agrícoles està organitzada en minifundis d'entre una i cinc hectàrees. Tanmateix, la citricultura a Borriana actualment no gaudeix d'èxit per diversos motius. S'han produït i acumulat una sèrie de problemes, de faltes de previsió i d'errors de coordinació en el món dels cítrics que, sumats a una nova conjuntura demogràfica i al desprestigi de la figura del llaurador en un món més governat per les grans multinacionals que mai, han conduït la citricultura borrianenca a la ruïna generalitzada. Només s'aguanten algunes cooperatives i empreses i finques grans, però els minifundis, ara com ara, estan condemnats a mort. Tot seguit analitzarem alguns dels handicaps que han provocat aquesta situació.

\subsection{Bon fruit, mal preu}

A hores d'ara, que la taronja ha perdut brillantor és una realitat que pot constatar qualsevol que contemple el paisatge litoral del País Valencià. La pèrdua de rendibilitat, l'especulació urbanística i la devaluació de la taronja han provocat un abandonament de terres massiu. Tot i així, el País Valencià encara és un dels magatzems citrícoles més importants del món.

Es coneix que les taronges, des que es cullen al camp fins que es venen al comerç, poden multiplicar per quatre el preu. Tanmateix, el llaurador és qui acaba rebent menys diners per la venda de la taronja en relació amb la despesa que ha fet per a cultivar-la. Si fem una aproximació al preu durant el processament, que comença al camp, un agricultor entre les podes, el maneig integrat de plagues, els adobs i el reg (que a Borriana és un poc més car, perquè encara està instaurat el reg per inundació en el 95\% de les parcel·les i no el reg per degoteig, que és l'òptim per a estalviar diners i aigua), pot arribar a gastar-se quinze cèntims per quilo de taronja. Si a aquest valor sumem els sis cèntims per quilo que li cobren per a collir la fruita, més un cèntim per a transportar-la del camp a la cooperativa, el llaurador 
s'ha gastat ja vint-i-dos cèntims per quilo de taronja, fet insostenible considerant el preu que es paga per cada quilo de producte al llaurador, com veurem tot seguit.

Per a calcular el preu que es paga per quilo a l'agricultor per les varietats de taronja més abundants a la Plana, ens hem basat en el darrer estudi del sector agrari valencià sobre les superfícies i produccions citrícoles a la província de Castelló durant la campanya de 2011-12 (GVA, 2013). A més a més, per a citar els preus que es paguen per varietats, hem consultat la llotja de cítrics, i hem calculat la mitjana dels preus pagats durant tota la campanya 201213 de cada varietat citada. El primer lloc quant a superfície ocupada i producció, l'ocupen les mandarines, amb un total de 34.447 hectàrees i una producció de 512.676 tones. La mandarina que més superfície ocupa és la coneguda com a clemenules (clementina de Nules), amb 22.963 hectàrees i una producció de 318.988 tones, que es paga a $0,24 € / \mathrm{Kg}$, seguida d'una varietat primerenca com la marisol, amb 1.517 hectàrees i una producció de 36.309 tones, que es paga a $0,31 € / \mathrm{kg}$. I, en tercer lloc, la mandarina orogrande, amb 1.451 hectàrees plantades, 22.755 tones de producció i un preu de compra de $0,24 € / \mathrm{kg}$. Les clementines, considerades com a mandarins-híbrids ocupen un total de 2.950 hectàrees i tenen una producció de 59.692 tones. En aquest grup es troben les varietats que poden obtenir un preu de mercat més elevat; en primer lloc la varietat nadorcott, que es va arribar a pagar sobre els $0,69 € / \mathrm{kg}$. També tenen millor eixida comercial que la clemenules les varietats fortune, que es paga a $0,49 € / \mathrm{kg}$, la clemenvilla, a $0,28 € / \mathrm{kg}$ i l'ortanique, a 0,28 $€ / \mathrm{kg}$, dins de les varietats de mandarins-híbrids. Una varietat primerenca, de la qual no hi ha molta superfície cultivada, és la clementina oronules que en la campanya 2011-12, es va pagar a $0,50 € / \mathrm{kg}$.

Amb menys superfície i producció tenim la taronja dolça, les nàvels són la varietat amb més superfície cultivada i producció: 4.607 hectàrees i una producció de 76.288 tones. La taronja navelate-lanelate és la varietat que més superfície ocupa (3.252 hectàrees) amb una producció de 61.314 tones, i es paga a l'agricultor a 0,24 $€ / \mathrm{kg}$. La segona taronja amb més producció, però molt lluny d'aquesta última, és la valència late, amb 915 hectàrees i una producció de 13.883 tones, que s'ha pagat durant l'última campanya a $0,26 € / \mathrm{kg}$. Una vegada la taronja arriba a la cooperativa, el preu és aproximadament de $0,22 € / \mathrm{kg}$. Ací, la taronja és seleccionada per mides, la netegen, l'enceren i l'envasen. Tot aquest procés té un cost aproximat de 20 cèntims per quilo. Així, hem arribat a un preu de $0,42 € / \mathrm{kg}$, que s'encarirà cinc cèntims si s'envia a Espanya i 30 cèntims si s'exporta a Europa.

En referència a les varietats anteriors, podem afirmar que el 57,44\% de clementines es dedica a l'exportació i sols el 17,5\% és destinat al mercat interior, mentre que per a la taronja, el 44,13\% és per a l'exportació i el 32,44\% es dedica al mercat interior. En totes dues classes es destina aproximadament un $10 \%$ a la indústria i un $13,5 \%$ són pèrdues $i$ minva.

Una vegada la taronja arriba als intermediaris, l'estructura comercial s'embutxaca un $25 \%$ per costos de distribució, que és el punt de processament més fort i que fa que molts dels agricultors es queden amb no res. Finalment, el comerç de venda al públic tindrà uns guanys d'entre quinze i vint cèntims per quilo. Per tant, el preu aproximat en finalitzar el processament dels cítrics és de $0,80 € / \mathrm{kg}$, la qual cosa vol dir que, durant aquest procés, el valor econòmic del cítric es quadruplica. 
Els preus que rep l'agricultor per quilo venut han baixat un $25 \%$ en clementines i un $11 \%$ en taronja entre 1999 i 2013 . Avui en dia, qui planta taronges té un $70 \%$ menys de beneficis que en el passat. Aquest és un dels principals factors que fa que el sector agrari dedicat a aquest cultiu haja disminuiit tant.

\subsection{Maneig integrat de plagues en cítrics}

Per a poder donar eixida a la taronja el més important és que el cultiu estiga sa. Si no hi ha un bon maneig integrat de plagues en el cultiu, probablement molts dels fruits que produeix el camp aniran al rebuig, fet que vol dir sempre perdre diners. Perquè el fruit estiga en bones condicions, tant per dins com per fora, cal controlar els agents que poden danyar-lo, i protegir-lo el màxim possible de les inclemències i de les agressions externes.

El maneig integrat de plagues (MIP) és una estratègia de control que consisteix en l'aplicació racional d'una combinació de mesures biològiques, biotecnològiques, químiques, culturals o de selecció d'espècies vegetals, de manera que l'ús de productes fitosanitaris es limite tot el possible. Aquestes mesures de control s'han de combinar amb la finalitat de mantenir els nivells de plaga per sota dels nivells que provoquen pèrdues econòmiques en el cultiu (llindar econòmic de danys). Per dur a terme un correcte maneig integrat de plagues és imprescindible: identificar tant la plaga com els enemics naturals (insectes beneficiosos per al cultiu) d'aquesta, dur un seguiment de les plagues en relació amb els llindars d'intervenció i, en darrer lloc, en funció dels resultats obtinguts, procedir a la presa de decisions donant prioritat als mètodes de control més respectuosos amb la salut humana, el medi ambient i els enemics naturals (Tena i altres, 2011).

En 2011, la superfície citrícola del País Valencià va començar a ser gestionada d'acord amb els reglaments de la producció integrada. L'entrada en vigor de la Directiva 2009/128/ CE del Parlament Europeu i del Consell, de 21 d'octubre de 2009, estableix un ús sostenible dels plaguicides. A més, es proposa que l'aplicació dels principis generals de maneig integrat de plagues siga obligatòria per a tots els productors europeus a partir de l'1 de gener de 2014, per la qual cosa es preveu que la superfície citrícola tractada amb mètodes del MIP augmente.

Des de l'Institut Valencià d'Investigacions Agràries (IVIA) i del Grup d'Investigació de Producció Vegetal de la Universitat Jaume I s'intenta implantar, de manera generalitzada, sistemes de producció a través dels quals es puguen obtenir fruites i verdures lliures de residus de plaguicides. En el cas particular dels cítrics, el coneixement adquirit al llarg dels anys d'investigació bàsica $\mathrm{i}$ aplicada en la gestió bioracional de les plagues ha permès a l'IVIA el desenvolupament d'una pàgina web i d'una aplicació per a telèfon mòbil de consulta molt recomanable per als llauradors (<http://gipcitricos.ivia.es $>$ ). Aquests llocs web naixen amb la intenció de convertir-se en una eina de consulta per a tots els professionals relacionats amb la citricultura. El web està estructurat amb la finalitat d'oferir un accés ràpid a tota la informació disponible dividida en diferents seccions: plagues principals $i$ secundàries (identificació, danys que pot produir, amb fotos de gran qualitat per a poder identificar-les, mètodes per poder mostrejar plagues i per a veure els diferents llindars d'intervenció i quin tipus d'estratègia es pot utilitzar, quin pot ser control biològic, control cultural o químic). A més, s'hi poden realitzar consultes personalitzades en funció de la 
varietat cultivada i època de l'any, preguntar com es poden aplicar productes fitosanitaris i els efectes secundaris que poden tenir aquests en els enemics naturals beneficiosos per al nostre cultiu (ja que no tots els insectes que s'instal·len en cítrics són perjudicials per al cultiu, i fins i tot alguns ajuden a controlar la presència d'altres insectes que sí que ho són).

\subsection{Jubilar la taronja. O no?}

Ara per ara sembla que l'agricultura no interessa com a sector regenerador d'una economia en crisi. Els governants han apostat, des de fa almenys vint anys, per un altre sector com a salvador de l'economia autonòmica: el turisme. Aquests governants intenten donar una imatge del País Valencià basada en el turisme (sobretot de platja, però també rural) $\mathrm{i}$ en la modernitat arquitectònica que traspuen algunes construccions, com el magnànim complex calatravenc de la Ciutat de les Arts i de les Ciències, o bé la futura Ciutat de les Llengües que volen construir al Grau de Castelló, l'aeroport, etc. Tot això queda molt lluny dels anys vint, trenta, seixanta i setanta del darrer segle, quan la taronja era un producte estrella de la nostra terra i es confiava en l'agricultura com un sector potent de l'economia. Encara queden, però, extenses terres planes plantades de tarongers arreu de l'orografia litoral valenciana que recorden aquest passat taronger esplendorós que caldria conservar en la memòria collectiva del nostre poble, com també repensar per a mantenir-lo des de la rendibilitat econòmica necessària i possible, en harmonia amb els altres sectors que puguen contribuir al benestar econòmic a través de l'ocupació laboral digna i diversificada dels habitants de les nostres terres.

Serà difícil de recordar aquest passat taronger amb decisions com la de tancar el Museu de la Taronja que es va prendre el 2012. Aquest museu, situat al carrer Major, ha estat promogut per l'Ajuntament $\mathrm{i}$ altres institucions $\mathrm{i}$ ha tingut com a gestores dues persones destacades de la cultura borrianenca: Vicent Abad i Enrique Safont.

Aquest santuari de la citricultura ens mostrava l'evolució citrícola a Borriana i el procés des que el fruit es collia de l'arbre fins que es venia als mercats d'altres països. A més, mostrava amb documents gràfics els canvis en el procés de comercialització de la taronja des dels inicis fins als nostres dies; la maquinària utilitzada per a fer aquesta feina i els productes de màrqueting, com ara els bonics papers de seda amb què s'embolicaven les taronges per al comerç. Les noves generacions ja no podran entendre ara tan bé com abans les nostres arrels agrícoles.

$\mathrm{Al}$ poc interès per la taronja i l'abandonament i expropiació de parcel·les citrícoles per a fer-hi carreteres, polígons industrials i reorganitzacions urbanístiques de sòl urbà, s’hi afegeix la manca de màrqueting. Actualment, no hi ha cap mena de màrqueting ni de campanyes publicitàries per a promocionar ni per a distingir la que diuen que és «la millor taronja del món». Res que faça que la nostra marca de taronja tinga una major eixida als mercats.

D’altra banda, la competència del Marroc ens guanya molt de terreny, tant pel que fa a la producció com a l'exportació. Encara que al nostre país els agricultors i els treballadors del camp guanyen, a hores d'ara, una misèria, als països africans com ara Egipte o el Marroc encara es paga molt pitjor pel mateix treball. Per tant, el preu de la taronja és molt més barat i l'única diferència a favor nostre rau en la qualitat de la fruita. Podríem dir que el maneig de cultiu al Marroc és semblant al que teníem a Borriana fa vint-i-cinc anys. 
S'hi utilitzen matèries actives (insecticides, fungicides i herbicides) prohibits perquè són perjudicials per a la salut humana. A més, les qualitats organolèptiques del fruit africà són inferiors a les de la nostra taronja.

Però un dels principals problemes que arrossega la citricultura borrianenca és l'organització en minifundis. Anomenem minifundis les parcel·les d'entre una i cinc hectàrees, que són les que ocupen el $90 \%$ de les parcel·les que tenim a la Plana. En aquestes parcel·les es cultiven varietats que dècades enrere es pagaven bé, però de les quals ha caigut dràsticament el preu de mercat. Pensem especialment en les clemenules i les navelines, clementines de bon gust, bona imatge i fàcils de pelar i que són les més abundants a la nostra marjal. Això significa que l'oferta ha superat la demanda d'aquestes varietats i per aquest motiu es produeix, des de fa deu anys aproximadament, la caiguda de preus. D'altra banda, en la majoria d'aquests minifundis es poden trobar més de quatre varietats de cítrics diferents. Per tant, encara és més difícil poder donar eixida a la taronja.

Aquestes raons, entre d'altres, fan que molts agricultors no vegen eixida al monocultiu dels cítrics. Per tant, i amb aires emprenedors, alguns s'han decidit pels cultius alternatius. Els llauradors busquen cultius amb baix cost de manteniment i amb una bona venda, per a tenir més beneficis que amb l'actual i deficitari conreu de la taronja. El kiwi, el caqui, l'alvocat, el magraner, el nesprer i altres espècies de fruiters ja es presenten com a cultius alternatius de la taronja.

\section{El futur de la taronja: algunes propostes prospectives}

\subsection{Cultius alternatius}

És molt fàcil dir que una de les solucions de la crisi de la citricultura pot estar en els cultius alternatius. Tanmateix, aquests no són la panacea, encara que sí que són una alternativa possible que cal tenir en compte. Molta gent ja no té interès per l'agricultura. Alguns han heretat l'hort dels avis o dels pares i l'han tingut com a sobresou fins que s'han adonat que aqueix sobresou que abans treien s'ha convertit en una despesa més que no compensa.

A Borriana poden cultivar-se gran varietat de fruiters i hortalisses perquè el sòl és molt ric (amb bones propietats físiques, químiques i biològiques). A la Plana, hi ha molt poques persones que es dediquen al cent per cent a l'agricultura, $\mathrm{i}$ amb la crisi econòmica en què ens trobem és difícil trobar solució als problemes actuals de la citricultura. Moltes parcel·les que hi ha a Borriana no són rendibles, i per a la gent és més fàcil deixar-les abandonades com un solar qualsevol esperant la venda que arriscar-se i intentar traure profit d'aquestes terres que hi ha sense treballar. Açò fa que es perda la illusió pel cultiu de la terra, un ofici molt vell.

Si tornem a la idea dels cultius alternatius, a Borriana, ja hi ha hagut algunes transformacions en alguns camps de cítrics on s'ha optat per l'alvocat, del qual alguns agricultors diuen estar molt contents perquè actualment es ven millor que la taronja i el maneig és molt similar. Al març de 2013, a Vila-real es va plantar una superfície d'unes 100 fanecades de caquis. A la província de València, s'ha estat plantant durant ja fa algun temps caqui i kiwi.

Abans de plantar qualsevol cultiu alternatiu al taronger caldria fer un estudi de viabilitat, tant agronòmic com econòmic del producte, per a no cometre els mateixos errors 
que en el passat es van cometre amb algunes varietats de cítrics. També cal estudiar els diversos paràmetres que influiran en aquest canvi de cultiu: conèixer el nou fruit, anàlisis climatològiques, del sòl, del maneig del cultiu (adobs, maneig integrat de plagues, reg, poda) de les dimensions del terreny, de la collita aproximada que es pretén obtenir i de les possibilitats de mercat. També variaria l'estudi de viabilitat en funció del que es vulga plantar en substitució dels cítrics. Per exemple, si es planten hortalisses, es pot jugar amb la rotació de cultius durant tot l'any sense deixar de produir (plantar una hortalissa o una altra segons l'època de l'any) i poder donar-li eixida comercial a tot allò que es cultive.

\subsection{Citricultura en línia}

Moltíssimes empreses al País Valencià han estat creades per a vendre taronges a través d'Internet. Llauradors, probablement aconsellats per familiars, amics o amb informació dels mitjans de comunicació, s'han decantat per la venda de taronges per Internet. La frase més representativa d'aquesta mena de distribució és «de l'arbre a la taula». En aquest tipus de negoci s'eliminen els intermediaris entre l'agricultor i el consumidor, i amb això el productor obté més beneficis. Dels 68 portals de venda en línia de taronges que hi ha al País Valencià, quatre són de Borriana.

Al consumidor li agradaria saber com ha estat cuidada aquesta taronja que comprarà per a confiar així en la qualitat. En primer lloc, que la fruita siga fresca i que haja tingut un bon maneig de cultiu. A més, si la fruita s'envia a qualsevol lloc, ja siga l'estranger o al mercat interior, ha de posseir un certificat sanitari i assegurar-se que aqueixos fruits no tenen cap mena de perill (plagues o fongs) a la destinació. El segon punt que reforçaria aquest tipus de negoci seria l'opció de poder vendre cítrics durant més temps, ja que haurien de combinar varietats primerenques, de temporada i tardanes. Probablement, d'aquesta manera s'abastaria molt més mercat i es podria oferir taronja durant els quasi set o vuit mesos que dura la campanya citrícola. Amb el desenvolupament d'aquesta opció l'agricultor obtindria un preu just per la fruita que faria que la seua feina fóra rendible.

\subsection{Seguir amb la citricultura?}

Sembla obvi que la citricultura mai no deixarà d'existir del tot a Borriana. Probablement per als xicotets propietaris, sí (minifundis); però, per a grans explotacions de cítrics, no. Això vol dir que els pocs agricultors que queden a la Plana, en el futur han d'abandonar la citricultura o han d'especialitzar-se en varietats de cítrics més rendibles. Per a començar a produir fruit, un taronger necessita aproximadament quatre anys, i per a ser competitiu amb la producció cal que passen tres o quatre anys més. Per això, no és molt viable alternar varietats de cítrics cada cert temps.

\subsection{Replantejament estructural en la citricultura}

Les varietats de cítrics estan plantades sense tenir en compte les varietats que ja hi havia plantades. Que vol dir açò? Doncs que durant l'època en què les clemenules i les nàvels van ser les reines dels cítrics, la majoria dels agricultors van plantar aquestes varietats. I quan 
la producció va ser excessiva, hi va haver saturació de mercat. En aquest punt comença la crisi a la citricultura. Es poden plantejar algunes alternatives per a poder reprendre $\mathrm{i}$ potenciar de nou la citricultura, encara que amb la crisi econòmica actual, aquestes idees poden semblar agosarades i, possiblement, hi ha dificultats per a implementar-les.

En primer lloc, es podria fer un replantejament estructural i varietal en la citricultura. Per a poder equilibrar els preus, caldria anivellar la quantitat de varietats de cítrics, eliminar varietats que ja no donen rendibilitat i plantar-ne d'altres que tinguen millor eixida al mercat. Abans de dur a terme aquests canvis varietals, caldria, però, portar a terme un estudi de viabilitat agronòmic i econòmic que avaluara diferents paràmetres com ara: les espècies que podrien donar rendibilitat, la quantitat d'hectàrees que farien falta per a cada varietat, els diners que aquest procés costaria, els beneficis que se n'obtindrien, el temps que es trigaria a poder obtenir-los o els costos del maneig de cultiu. Aquest estudi de rendibilitat del canvi varietal és una idea fàcil de pensar, però difícil d'aplicar. A més, fer comprendre a un llaurador que ha d'arrancar tot el seu hort de clemenules, que probablement és la millor clementina del mercat, per a plantar-hi una altra varietat de menys qualitat, és possiblement difícil de copsar. Probablement, es necessitarien estímuls de reforç al sector, com ara ajudes o subvencions per als agricultors per a motivar-los a dur a terme el canvi varietal.

\subsection{La investigació citrícola}

Amb la instauració de la producció integrada a la citricultura, equips d'investigació del País Valencià, com ara els de l'IVIA o l'UJI, es continuen estudiant plagues clau que causen danys als cultius de cítrics, acompanyats de pèrdues econòmiques. Les plagues clau són aquelles en què l'ús del control biològic no arriba a ser satisfactori i les densitats d'aquestes plagues es troben normalment per damunt del llindar econòmic de danys. En aquest grup podem trobar: el poll roig de Califòrnia (Aonidiella aurantii), els pugons (Aphis spiraecola i A. gossypii), la coneguda mosca de la fruita (Ceratitis capitata) i l'aranya roja (Tetranychus urticae).

Han estat molts els estudis satisfactoris d'aquests grups d'investigació, els resultats dels quals s'han publicat en revistes d'alt impacte, i s'han consolidat com a grups capdavanters en el control d'aquestes plagues clau. Probablement, si se segueix el mateix camí, cada vegada s'obtindran més opcions per a aplicar aquests tractaments no químics ni nocius a la citricultura. El cultiu ecològic (lliure de tractaments químics) podria potenciar l'increment de venda de taronges, encara que com s'ha dit abans, les plagues clau de vegades són difícils de controlar. Hi ha danys que no perjudiquen la qualitat organolèptica de la taronja, com per exemple els danys de poll roig i d'aranya roja, que són merament estètics. Per a promoure la realització d'agricultura ecològica en la citricultura, hauria d'haver-hi xarrades divulgatives on es posara èmfasi en el fet que els danys estètics no alteren la qualitat de la fruita. La realitat és que els danys estètics produeixen molt de taronges de rebuig. Per aquesta raó es realitzen els tractaments químics, per a evitar que aquests danys produïts en la pell del fruit no apareguen i, d'aquesta manera, la taronja siga comercialitzable. Aquest plantejament dels horts ecològics també podria donar-nos bons resultats, relatius a la venda i a la disminució de costos, i un poc menys de contaminació per a l'agricultor. 


\subsection{Millora del màrqueting}

Si en l'actualitat hi haguera un mínim de màrqueting, probablement augmentaria la demanda de taronja i els mercats s'animarien perquè molts voldrien tenir per als habitants del seu país una taronja amb els nivells organolèptics de la qualitat del nostre fruit. Es pot discutir sobre aquest tema, però la taronja del nostre terreny no té res a veure amb les altres que hi ha cultivades fora del nostre país. Per a explicar-ho, en primer lloc, li hauríem de donar la importància que té, hauríem de fer xarrades divulgatives, publicitat en premsa, pamflets informatius i altres iniciatives per a explicar la qualitat del producte cítric valencià i la diferenciació amb altres llocs de cultiu. Possiblement, aquest increment en bones campanyes de publicitat podria donar opcions a obrir portes en molts mercats per a l'exportació. Si alguns horts s'animaren a realitzar citricultura ecològica, encara que és molt dificultós, pel maneig de plagues, es podria incidir en aquest punt que tant motiva el comprador els darrers temps. A més, un dels llocs més importants per on caldria començar és la proposta d'un segell de denominació d'origen de la taronja valenciana.

\section{BIBLIOGRAFIA}

Abad García, V. (1984): Historia de la naranja (1781-1939), València, Comité de la Gestión de la Exportación de Frutos Cítricos.

Aparici VIlar, J. (1993): L'agricultura al terme de Borriana, Borriana, Agrupació Borrianenca de CulturaPublicacions de la Universitat Jaume I.

Font de Mora i Montesinos, L. (1971): Taronja i caos econòmic, Barcelona, Edicions 62.

Generalitat Valenciana / Conselleria d'Agricultura (2013): Estadísticas: Precios agrarios, <http:// www.agricultura.gva.es/la-conselleria/estadisticas/precios/precios-agrarios>.

InSTITUt VALENCIÀ D'EXPORTACIONS (2013): <http://www.ivex.es/dms/estudios/informacion.../ CITRICOS\%20CV2013.pdf (Accés 25/09/2013)>.

López Gómez, A. (1957): «Evolución agraria de la Plana», Estudios Geográficos, 67-68.

MAGRAMA. Anuario de estadística del Ministerio de Agricultura, Alimentación y Medio Ambiente (2012): <http://www.magrama.gob.es/estadistica/pags/anuario/2011/AE_2011_Avance.pdf (Accés 12/10/2012)>.

Roca i Alcaide, F. (1932): Historia de Burriana, Castelló de la Plana, Imp. Armengot.

Sarthou Carreres C. (1989): Geografía general del Reino de Valencia. Provincia de Castellón, 1912, Castelló, Caja de Ahorros y Monte de Piedad de Castellón.

TenA, A. i altres (2011): «Gestión integrada de plagas en cítricos: aplicación práctica», Phytoma España, 239, 30-36.

Urbaneja, A. i J.A. JaCas (2008): «Tipos de control biológico y métodos para su implantación», dins JACAS, J.A. i A. Urbaneja (eds.): Control Biológico de Plagas Agrícolas, Phytoma España, 151-164.

\section{BIONOTA}

\section{Pablo Urbaneja Bernat}

(Borriana, 1986) Enginyer Tècnic Agrícola per la Universitat Jaume I de Castelló en 2009. Màster oficial en Protecció Integrada de Cultius per la Universitat de Lleida en 2011. Ha presentat una Tesi de màster que porta per títol: Improved methods and uses related to rearing of a zoophytophagous insect and crop protection. En 2012 obté una beca FPI per realitzar la tesi doctoral a la Universitat Jaume I i a l'Institut Valencià d'Investigacions Agràries (IVIA), titulada: Enginyeria de xarxes tròfiques en advocat i cítrics: millora del control biològic i efecte de les condicions ambientals en interaccions tri-tròfiques de rellevància. 